\title{
A Biography of the Titanic: Reuse, Rumours and Myths Constant Sinking and Resurrections Through Stories Spectacular
}

\author{
Apoorva Singh
}




\begin{abstract}
It is not an exaggeration to say that Titanic is synonymous with myth-making, its stories and history itself is the cause of its status as a 'Modern Myth' or even a legend. Titanic epitomizes the 'construction of a myth' from large scale to the very minutely detailed. All that is popularly known of Titanic is arguable and full of fictional retellings. Even if some truths are known, the discovery of the truth of the Titanic disaster will always be incomplete. And so instead, I shall strive to find the rumors associated with it, and how the amalgamation and the dissemination of said rumors contributed to the Titanic myth and its status as an urban legend. The story of Titanic is the story of human culture and the Titanic disaster is the most potent cultural happenstance of the modern world- an unbroken fascination from the very first day. My medium of study will be the cinematic conceptions of Titanic, quiet a few to name and internationally a brand. From the early moving picture documentary In Nacht und Eis and the first talkie Atlantic to the latest cultural influence James Cameron's Titanic. This will shape up the cultural reach of the Titanic tragedy through its representation and appropriation in world cinema- spatially and temporally.
\end{abstract}

Keywords: Titanic, reuse, rumors, myth, myth-making, legend, cinema 
"I am not consoled by the false, written-up, Drury Lane aspects of that event, which is neither drama, nor melodrama, nor tragedy, but an exposure of arrogant folly."

$$
\text { -Joseph Conrad }{ }^{1}
$$

In many ways, the above quote summarizes the history and understanding of the Titanic. The underlined aspect is always going to be the 'exposure of arrogant folly', when the disaster first struck to the time it became a metaphor, Titanic was the result of the act of God, putting fear into the overconfidence of humanity. This was the consolation that the masses gathered from the suddenness and seemingly meaninglessness of the Titanic tragedy. Very soon, it became shrouded with inexact 'truths'. Like the belief that the Titanic tragedy was the worst maritime disaster of the modern world, especially because it happened in a peaceful time ending its long run, and was the oft emphasized pride of British naval supremacy.

The story has been interpreted in many overlapping ways, including as a symbol of technological hubris, as basis for fail-safe improvements, as a classic disaster tale, as an indictment of the class divisions of the time, and as romantic tragedies with personal heroism. It has inspired many moral, social and political metaphors and is regularly invoked as a cautionary tale of the limitations of modernity and ambition. (Wikipedia)

This 'exposure of arrogant folly' was central to the depictions of the Titanic story. As stated above, it exposed the arrogance of technology, the arrogance of human superiority validated by the construction of large mechanicals- the Titanic ship in this case, the arrogance of human society conveniently divided along class lines and the arrogance of being British. The last one because the retellings of this disaster included the praise of the British nationals who behaved admirably, only as British men could, because of their inherent superiority. ${ }^{2}$

\footnotetext{
${ }^{1}$ Joseph Conrad, a Polish-British writer. 1857-1924.

2See Rudyard Kipling's "The White Man's Burden” for a concrete emphasis.
} 
This paper seeks to explore the myth making of Titanic through presentation and participation. How factors involved in the making of an urban legend from a clearly historical event ranged from the myth of technology to the myth of disaster. The entirety of this titanic narrative lies in the human response- to disaster, to chaos, to arbitrary 'acts of God' and the loss of the creamy layer first class citizens. Because the talk of the town is not the third class passengers, who are simply in the picture, but the noble, Godlike response of the first class people.

This paper also seeks to explore how the meaning of visual signs is manipulated through the process of transculturation ${ }^{3}$, applied to the key symbol- Titanic. A historical case study of its cinematic adaptations is carried out to analyse how new meaning is created and manipulated to generate versions of it. It is understood from this study, that timing, control, history and universalism are key factors for the transculturation of the phenomenon called Titanic.

Although of course there will be no pomposity of authorial claims to objective assurance. ${ }^{4}$

The nature of transculturation may be observed in the cultural exchange between individuals and their community, which is a two-way process, wherein all participants are transmuted. This dynamic process is explored through visual signs- the cinema in this case. It is the psychology of perception that guides in the definitive impact of cinema.

\footnotetext{
${ }^{3}$ Coined by Cuban anthropologist Fernando Oritz in 1947 to describe the phenomenon of merging and converging cultures. In the case of this paper, it is the various cultural implications of the respective Titanic films.

${ }^{4}$ Irving Singer, 2008. In the prefatory note of his book Cinematic Mythmaking-Philosophy in Film.
} 
Wittkower (1977) indicated that transculturation reaches back as far as the beginning of civilization itself and is based on universal or common elements as a foundation for the transculturation process. Although language is a key factor in the process of transculturation, visual signs may be even more powerful (Horn, 1998).

But before delving into the fascinating aspects (like rumors and the films themselves) of the Titanic story, I will make room to engage with the equally fascinating aspects of reality that it must have dealt with, both prior to the launch and during the travel itself. One of the foremost concerns with the disaster were whether the Titanic was duly inspected and cleared for marine navigation. Due to the oft repeated 'facts' that there were no drills, the crew was untrained and the lifeboats were not enough due to negligence etc., it has become something of a face value fact without thorough background checking. It is indeed a fact that blockbusters (Cameron's Titanic in this case) make for a disastrous official account, for their reach and cinematic thrill makes audience susceptible to the film's narrative as being an official account making it nearly impossible to separate fact from fiction and therefore have tremendous myth celebration instances rather than historical accuracy. It is imperative then that there be historiographical checks every time there are conspiracy theories, for example, the one that maintains that the Titanic had a deliberately flawed construction and ignorant crew. Upon inquiry etc., it was found that the standard regulations (admittedly outdated, belatedly realized of course) of maritime travel were in fact followed, not to an excellent level but a satisfactory extent, which would otherwise have been overlooked if not for the 'essentially meaningless' disaster that followed. While most of the faults in question were engineering issues- like not enough capacity for lifeboats, no large addressing/ notifying system to alert the passengers and the inadequacy in 
sealing the holds after flooding or even pumping out the bilge water quickly and efficiently enough; there were also the human issues, one, that most of the third class passengers were 'aliens' and either did not understand English or were falsely assumed by the crew handling evacuation and two, that everyone onboard including the seemingly mismanaged crew, was unprepared to handle a situation of this magnitude. Mostly because the majority of passengers who were 'in the know' almost immediately were first class and were ill equipped to face an emergency first hand. This is of course a risky claim to make, but it's never said otherwise, anywhere, even in the face of such tragedy. What was and is talked about, even after a century, is that their noble position in life gave them many virtues to accept and live through the disaster.

Engineering aspects of the disaster are discussed in the leading article in Engineering for April 19 ... [S]everal questions present themselves as ripe for discussion and settlement. The effect of centre-line or longitudinal wing bulkheads is one of these. Such have advantages in confining any water admitted to a part of the width, but have disadvantages even from the point of view of stability under disastrous conditions. The effect of impact on the superstructure of very large ships will have to be considered. (Nature, 2012)

There are as many ideas about the cause of sinking of the Titanic as there are retellings. Were the materials weak? Was the actual building process in accordance with the regulations and standards of the time? It is imperative to note that the standards and other regulations did change for the better after the disaster to prevent further tragedies like the wireless telegraphy being monitored $24 / 7$ by operators and watertight bulkheads. During the early $20^{\text {th }}$ century, the internal combustion engine and gas turbine replaced the steam engine in most ship applications. Transoceanic travel: trans-atlantic and trans-pacific, was a particularly important application; with 
ocean liners replacing steam powered sailing ships, culminating in the massive Superliners which included RMS Titanic. The tragedy of the Titanic led to the 'Maritime Distress Safety System'. (Wikipedia)

Yet the questions remain and doubts still fester in the popular imagination, unsatisfied.

The makers of the ship weren't amateurs. They were practiced professionals in the exact kind of ship building, but mostly on a bit smaller scale, for the Superliners were unique to their kind. As a frame of aesthetic experience, the Titanic was second to none. The trio of designers Thomas Andrews, Alexander Carlisle and Edward Wilding collaborated to make the engineering and opulent marvel. Harland and Wolff, the actual builders of the Titanic weren't amateurs either. They had been involved in similar kinds of ship building.

So what was it that went so wrong for the Titanic? Was it financial issues that led to the use of poor quality materials? It was said that the ship had been designed to prevent sinking in case of water flooding. It was intended that the compartmentalised hull would close off chambers full of water and prevent seepage into other areas. These said compartments were 'water-tight' and 'sealed off', which would prevent a ship from sinking, theoretically. A lot of Titanic's regulations were theoretical it turned out- from the drill run of lifeboats not lowered completely down to go through a thorough checking, to missed drills because Sunday and the Captain's confidence and the promise of 'designed to be unsinkable'. These compartmentalised hulls, though, were useless when the iceberg hit and started flooding the ship at an alarming rate. Due to the poor standards of the time, the Titanic was doomed from day one. 
At the time when the Titanic was lost the standing Advisory Committee appointed by the Board of Trade under the provisions of Merchant Shipping Acts was engaged in the reconsideration of the regulations for boats and life-saving appliances ... The main recommendations of [their] report may be summarised. First, it is recognised that "the stability and seaworthy qualities of the vessel itself" must be regarded as of primary importance. This includes the question of watertight subdivision, now under investigation by a special committee. Second, as regards boats and life-saving appliances it is recommended that accommodation should be provided for the total number of persons which each foreign-going passenger steamship is licensed to carry ... One of [the committee's] most valuable recommendations is that proposing to extend the present regulations and to prescribe to those in charge of ships the necessity for proceeding at moderate speed "at night in the known vicinity of ice."

From Nature 29 August 1912 (Nature, 2012)

Which is possible because commercial ships- ocean liners of luxury were relatively new and the might of the British empire lay on its military naval supremacy. Perhaps their competition with the German military navy caused them to overlook the design and safety standards required for such a large undertaking. Perhaps it was the same reason that led to negligence and overachieving of the British capitalist class. If, to any extent, the latter is correct, then the 1943 German Titanic film wasn't too wrong in accusing the British arrogance and greed for the sinking of the Titanic and the loss of the many people onboard. The very construction of the Titanic and its sister ships- Olympic and Britannic, was the result of competition with the rival ship company Cunard. To compete with the world breaking speed of its rival, White Star Line, the maker of Titanic, made these three superliners as an epitome of luxury and extravagance rather than merely speed. This further emphasised the class differences both in the 
now dying British society (and empire), and within the ship's passengers who were harshly segregated.

Many theories developed to accommodate the strain and shock of a massive ship sinking so rapidly. Were rivets that tied the ship together to blame? Or the hull that couldn't bear the strike of an iceberg? There are actually three concrete theories that are accepted by experts to have been responsible for the sinking of the ship: a, the rivet theory; $b$, the hull theory; and $c$, the weak materials theory. While these theories could potentially be blamed, in the long run it becomes rather useless. It's almost never a scientific answer that the populace is looking for. There is no room for boring facts in the popular imagination. It's wonder and fascination that is frequently sought and found.

And this wonder and fascination has sufficiently been exploited in the cinema. Titanic in the popular imagination has had an epic, almost never-ending impression. The Titanic is a symbol that has had tremendous impact across time and culture. The pinnacle of its use is as a (subtle) propaganda by the respective cultures (nations) set in the strategies employed by various makers of these films. In order to examine and elucidate how the Titanic story is appropriated as a pop cultural phenomenon by Britain, Germany and the US, I will specifically focus on the Titanic representation in its cinematic adaptations of the aforementioned countries which incidentally covers both sides of the Atlantic. Due to the pervasiveness of this medium with its voracious consumption, it provides us with an unmarred lens, a photographic intransience, seen exactly as it was in its first rendering. They are not just carriers of meaning on different levels, but also give us clues of the time they were created in. These films have worked as propaganda channels used not just by totalitarian powers but also as a soft, hegemonic power, which is really where the true art of propaganda lies. 
Often overlooked in the more 'formalistic' approaches in art history, cinema is a key component of visual culture, sharing much in common with the oldest of visual expression forms- painting. It will not be a stretch to say that much of cinema's form, function and style owes itself to the tradition and innovation in painting. The vocabulary of film and painting is elaborately similar. There is a mutual respect and understanding of the two- sometimes an integration that needs to be explored. ${ }^{5}$ As a facet of art history, cinema is most approachable.

I shall of course then inspect and explore the more focused vision of reuse in cinematic art- in the making of myth as a development to the legend of Titanic.

From the moment news of the sinking broke, the story of the Titanic became encrusted with myth. Because it went down at a time of acute tension and disturbance (unlike the popular belief of a lengthy peaceful time) in both Britain and the US, the Titanic story provided the opportunity to underline and affirm the basic values of culture and a social structure that were under threat. Each of the key stories associated with the disaster provided evidence of real-life conduct based on enduring values and served to refute the ideas of socialism, feminism and anticapitalism that were challenging the status quo. It was as if God had decreed that things remain the way they were in terms of 'isms' by sinking the hubris of mankind. The order of evacuation (women and children first) reemphasized the helplessness of women who needed the stoic and self-sacrificing male protectors. The story of Mrs. Ida Strauss who chose to perish with her husband of 40 years confirmed the sanctity of marriage and refuted those who claimed it to be patriarchal tyranny. Benjamin Guggenheim and his valet's endorsement of codes of chivalry (a shared tenet of the shared cultures of Britain and the US) by dressing in their finest and being “prepared to go down like gentlemen" was emphasizing the dominant model of masculinity.

\footnotetext{
${ }^{5}$ See Johannes Vermeer and Peter Webber's The Girl with the Pearl Earring.
} 
By contrast there was panic among the 'Latins' who were instigating it all over the third class (because there were British $3^{\text {rd }}$ class passenger too). This is instrumental in the construction of a 'national' myth- the belief that the Anglo-Saxons were the superior among humanity's races. Only consequentially different from Hitler's Aryan supremacy theory. Of course another scandalous claim, but only because one is closer and clearer in the human memory. And obviously more popular. There is no reason to have forgotten the Rwandan genocide. Maybe we all suffer from superiority complex, only on a smaller, easily ignored and less vehement scale.

Like all things, the Titanic myth is also equally populated by positive, uplifting myths and the more darker, gruesome ones. Of the former is the supposedly "Be British" of Captain Smith and the more corroborated 'Nearer, My God, to Thee' hymn played by the ship's band till the very end. Of the latter is of course the class discrimination in passengers, in their evacuation and their vilifying.

In hindsight, it would seem that there was an extraordinary rush to turn the sinking of the Titanic from a tragic, perhaps even a criminal, (even I can't seem to resist) event into something of deeper significance. The first among these decisive actions was the way the ship was retroactively named 'The Unsinkable'. The pull to a particular kind of mythology was so strong that ever since, there survives an obsessive desire to probe the 'truth behind the Titanic'. To this day, there is a club of interested people with its own publication, 'The Titanic Communicator'. Richard Howells shows the way the sinking of the Titanic provided a metaphor and a mythic narrative to sum up the significance of 'modernity'. The Titanic's sinking was quickly embedded within discourses of human hubris and 'Nature's' response. Real human mistakes, failures and responsibilities were mythified and provided a long-lasting story of overweening 
human ambition, bathed also in stories of passing class arrangements and the cultures that accompanied them.

Cameron's Titanic was by no means the first film version of the sinking and its consequences. Within three months of the event, a silent movie version starring one of the survivors (Saved from the Titanic, 1912) had been rushed out. This was the first among many more to follow. It was coincidentally a film actress, Dorothy Gibson.

Next was the German film version, Night and Ice (Titanic: In Nacht und Eis) . Directed by Mime Misu, and shot in 1912 on a real liner and running for about 40 minutes, it contained 10 scenes. The film had an international release and was of course widely received.

The first talkie to recreate the Titanic tragedy was Atlantic (1929). It was historically inaccurate and heavily shielded from claiming a genuine reproduction. Its only claim to fame is being the first talkie about Titanic, even vaguely. There was a 'grandiose but pretentious' German version and the seemingly American, US version. Although they were all by the same director, there were noticeable variations.

The truly propagandist film about Titanic was the German 1943 version which was commissioned by Goebbels. The Germans were truly fascinated with the tragedy of the Titanic and this was their $3^{\text {rd }}$ remake. Although the film remained unreleased in Germany it was opened in other European countries. This was because the entire structure and form of the film was changed to glorify the Germans in their Aryan supremacy and vilify the Britishers, comically, as greedy and autocratic in nature. Insatiable in their lust for money and vice. The premise of the film though, severely resonated with Goebbels as something too close to home and thus the film failed to work as it was originally intended to. 
The epic British film A Night to Remember (1958) based on the Titanic doyen Walter Lord's book of the same name, is the truest depiction of the Titanic tragedy. As a British film, it enjoyed proximity with the story and representation.

But important as all these are, perhaps just as important is what Titanic did for the audiences. Its mixture of disaster, special effects and romantic ideals was a potent universaliser, attracting both men and women, couples and families, young and old. That is why Titanic has been so subtly successful as a propaganda.

Like the Chachnama (Asif, 2016) is ostensibly meta in its approach, the Titanic cultural legacy is too. The former is a book recounting and interpreting the story of a book that has historical origins but a mythic status, and the latter is the story of the making of a myth as a modern solution. It is the palimpsests of time and space that the original 'Book of Conquest' was about, multiple almost non-linear stories or histories that seems linear but encompass its happenings and retellings. A 'bloody story' as an 'account of the Islamic beginnings of the state' (Naipul, 1981), in a Hindu Indic kingdom of Sindh. Asif's Chachnama is a patchwork of several literary and historical genres-part fact and part fiction. (Wink, 2017) And so is Titanic. It is a historical patchwork account of official inquiries, survivors and witnesses. And it's palimpsest is the changing orientation of its meaning and interpretation, recently resurged in 2012 due to the capsizing of the Costa Concordia, also a cruise ship.

Of course the facets seem to be reinforced when thinking about Baxandall's Patterns of Intention, which is 'an enquiry into the historical understanding of pictures'. This is what I have attempted to do with the films of Titanic- a sense of the creators' goal and their disentanglement of meaning as a manifestation of the authentic drawn from root cultures and projected onto the market audience. Baxandall does not claim that inferential criticism isn't the only method to 
think about pictures, but if we accept that behind a superior picture there is a superior organization-perceptual, emotional and constructive-it seems evident that attempting to discover the artist's intentions will sharpen our legitimate satisfaction in the picture itself.

A vastly different palimpsest is offered and explored in Barry Flood's essay “... Translating the past in Sultanate Delhi". His kind reveres the past and tries to position itself as a linear lineage of greatness that is being acknowledged as it is being succeeded. This kind of an understanding is missing in the Titanic films. They are about manipulation and propaganda and sometimes, as in Cameron's, a fooling backdrop.

As both myth and rumours can be called urban legends, due to their unreliability and lack of credibility, Titanic has the privilege of being all three.

Titanic itself is a narrative of 'Euhemerism' myth (after the mythologist Euhemerus, c. 320 B.C.E.) which are a kind of historical distortion myths. These myths arise from real historical events and elaborately repeated by storytellers until those 'accounts' gain the status of Gods. I think, the paper is evidence enough for this.

Titanic is also an 'Allegory' myth which states that myths have their origin in nature (Apollo as Sun), philosophy or spiritual concepts (Nike representing Victory). Muller ${ }^{6}$ supported an allegorical theory of myth. He believed myths began as allegorical descriptions of nature and gradually came to be interpreted literally. (Wikipedia) Titanic is not only the allegory of the act of God in the face of humankind's futile pomposity, but also nature's rebuke to human arrogance.

The Titanic myth has worked itself into modern discourses, its rumours like 'Be British' has become English language slang. As a modern myth, Titanic explores what it is to be human.

${ }^{6}$ Friedrich Max Muller, 1823-1900. German Philologist and Orientalist. 
Some of these myths reflect people's fear of rapid social change or of science and technology; others appeal to their desire to find meaningful patterns beneath the confusing chaos of ordinary life. (Wikipedia)

The real issue that these films address and intertwine with are myth and history, both of which are interrelated because the mythology is the result of historical events or situations. The Titanic myth draws from its own historical position. It combines historical fact, canonization of personages, and attributes of piety, bravery and a sense of accomplishment. The Titanic propaganda and legacy took various foreign and domestic elements and systematically adapted and manipulate them to create something new each time, but also something that is a part of the larger oneness and legacy of the 'unsinkable ship'. 
The conclusion of this paper help us to understand how entangled all things Titanic really is, and how the evolution of the Titanic story has been the propagation of an urban legend. Research constraints are due to the historical nature of this phenomenon, the limitations of the primary sources and the inevitability of the traps of the process which examines in-exactitudes and fluid nature of the subject. The 'meta' nature of the project is both a constraint and a liberation. This is a paper that is studying not the tragedy of the Titanic as it happened but its ripples of the consequences- essentially, the human factors. It is difficult to put neat boundaries in the mess of rumours, but there is an attempt. And a further study based on the existing one would prove further clarity- it is difficult to build from the ground up.

It can further be taken as an interdisciplinary approach and agenda. A clearer understanding of causal relationships, sequence and relative importance within the parameters specified would increase the validity of the paper. The haze surrounding the Titanic is in itself a definitive meaning. Even with all the transculturation, there is an ominous focal point known as Titanic in the modern history. It may even start an intercultural dialogue worthy as a beneficent sign. 


\section{The Never Ending Story}

The Titanic has had two lives. Its first life was as an ill-fated ship that floated for less than a year. Its second life began the moment the ship struck the iceberg and, almost 100 years later, shows no sign of ending. With countless films, books, musicals, songs, computer games, and websites to its name, the Titanic is now more famous than ever. Phrases associated with the ship"tip of the iceberg," "rearranging the deckchairs on the Titanic," "and the band played on"-have all entered the English language, and there can be few people who do not have some knowledge of this fascinating story. Even those who have no interest in ships or the sea have been touched by the tragic tale of the Titanic and the shocking waste of lives. The Titanic may lie rusting at the bottom of the Atlantic, but interest in the ship-and the magical era it was a part of-lives on. 


\section{Bibliography}

- Howells, Richard. 2012. The Myth of the Titanic. Basingstoke: Palgrave Macmillan.

- Howells, Richard, and Robert S. Matson. 2009. Using Visual Evidence. Milton Keynes: Open University Press.

- Richards, Jeffrey. 2003. A Night to Remember: the Definitive Titanic Film. London: I.B. Tauris.

- Howells, Richard. 1994. The Interpretation of Popular Culture as Modern Myth.

- “The Unsinkable Myth.” 2012. Th/.

e Public Domain Review. April 11, 2012.

https://publicdomainreview.org/2012/04/11/the-unsinkable-myth

- Lynch, Donald, Ken Marschall, and Winthrop Sears. 1992. Titanic: an Illustrated History. New York: Hyperion.

- McIver, Gillian. 2017. Art History for Filmmakers: the Art of Visual Storytelling. London: Fairchild Books.

- Koldau, Linda Maria. 2012. The Titanic on Film: Myth versus Truth. Jefferson, NC: McFarland \& Company. 


\section{References}

- Horn, R.E. (1998). Visual language: Global communication for the 21 st century. Bainbridge. Island WA: MacroVU, Inc.

- Wittkower, R. (1977). Allegory and the migration of symbols. Boulder CO: Westview Press.

- Naipul, V.S. (1981). Among the Believers: An Islamic Journey. England: Andre Deutsch.

- Andre Wink. Review of Asif, Manan Ahmed, A Book of Conquest: The Chachnama and Muslim Origins in South Asia. H-Asia, H-Net Reviews. May, 2017. URL: $\underline{\text { http://www.h-net.org/reviews/showrev.php?id=47738 }}$

- "100 Years Ago: The Loss of the 'Titanic." 2012. Nature News. Nature Publishing Group. April 11, 2012. https://www.nature.com/articles/484174a 